\title{
Addressing Racial Disparities in NIH Funding
}

\section{Nicole Comfort}

Columbia University Mailman School of Public Health, Department of Environmental Health Sciences, New

York, NY, USA

https://doi.org/10.38126/ISPG180408

Corresponding author: nicole.comfort@columbia.edu

Keywords: National Institutes of Health; funding; systemic racism; equity; STEM workforce; diversity

Executive Summary: The United States (US) must strategically invest in diversifying its biomedical workforce to retain global leadership in biomedical research and to reduce racial and ethnic disparities in the US. The under-representation of minority groups in the biomedical sciences is influenced by the National Institutes of Health (NIH) grant funding process which relies heavily on peer review subject to bias. Despite recent initiatives to combat structural racism within the $\mathrm{NIH}$, the NIH has done little to rectify racial disparities in funding allocation that have been known for over a decade. In this report, I evaluate current NIH proposals to reduce bias in peer review and present stronger policy options for reducing inequity in grant funding. I recommend that the NIH treat the race/ethnicity funding disparity as it did the early career investigator disparity and immediately relax paylines and simultaneously prioritize research topics that align with interests of under-represented investigators, while working to develop a modified lottery for grant funding as a long-term solution to the biases that can influence grant peer review. Policies to address disparities in grant funding will diversify the biomedical workforce and have a profound and long-term positive impact on providing equitable access to science careers, regardless of race.

\section{Statement of issue}

In order to maintain global scientific competitiveness and leadership, the United States (US) must expand the participation of under-represented individuals in science, technology, engineering, and mathematics (STEM) (McGee, Saran, and Krulwich 2012; Bianchini 2011). Together, Hispanics, African Americans, and Native Americans represent over $30 \%$ of the US population, but less than $9 \%$ of STEM Ph.D. recipients are members of these groups (McGee, Saran, and Krulwich 2012; US Census Bureau 2019) and even fewer hold faculty positions (Association of American Medical Colleges 2018; National Center for Education Statistics 2020). Despite efforts to increase the number of students from under-represented groups majoring in the biomedical sciences (McGee, Saran, and Krulwich 2012), a higher number of Ph.D. degrees conferred to scientists from underrepresented backgrounds does not translate into higher numbers of faculty positions for these scientists (Gibbs et al. 2016; Finkelstein, Conley, and Schuster 2016).
This disparity is heavily influenced by difficulties under-represented researchers face when establishing their career, including success in research funding. A landmark 2011 study found that grant applications from Black investigators were $10 \%$ less likely to be awarded research funding from the US National Institutes of Health (NIH) in the form of Research Project (R01) grants compared to their white colleagues, even after correcting for various factors such as the applicant's educational background, country of origin, and typical measures of scientific achievement (Ginther et al. 2011). Funding disparities for Asian and Hispanic investigators have also been reported (Ginther et al. 2011; Ginther, Kahn, and Schaffer 2016). The existence of systemic racism in scientific funding is a major barrier to the success and advancement of researchers from historically under-represented groups and contributes to decreased diversity among STEM faculty (Dzirasa 2020; Taffe and Gilpin 2020).

The US has long been an established pioneer in STEM but is quickly losing its position as a global leader in 
biomedical research and innovation (Dzau and Fineberg 2015; Moses et al. 2015; Sekar 2020). In addition to meeting workforce needs (Benish 2018), diversification of the STEM labor force will strengthen the biomedical science talent pool and ultimately contribute to greater innovation and productivity and the critical need to reduce racial and ethnic health disparities in the US (McGee, Saran, and Krulwich 2012; Thomas and Ely 1996; Bianchini 2011). Despite longstanding efforts at the NIH to increase the diversity of its biomedical research workforce (McGee, Saran, and Krulwich 2012), little has been done to address inequities in allocation of research funds. According to the $\mathrm{NIH}$, the gap in funding success of R01 grants has not closed; in fact, between 2013 and 2020, it only decreased 2\% for Black investigators (NIH 2021a). It is unacceptable that this funding gap still persists a decade after the disparity between Black and white principal investigators was exposed. As the US is proposing to increase federal research spending (The White House 2021; Tollefson et al. 2021), now is the time for immediate and effective action from the NIH to right this inequity.

\section{i. NIH grants for career advancement}

Racial inequities in NIH grant funding contribute to less diversity among faculty, further perpetuating under-representation of minority groups in biomedical fields (Fairle, Hoffmann, and Oreopoulos, 2014; Taffe and Gilpin 2020). Established investigators with prior funding success benefit from the so-called "Matthew effect" - the idea that "the rich get richer," i.e., funding, resources, and prestige bestow further rewards and future funding success (Merton 1968). This is because the current system emphasizes applicants' funding track record over the strength and ingenuity of their research ideas (Merton 1968; Taffe and Gilpin 2021). Importantly, record of NIH funding is required for retention and promotion in many academic departments. Thus, racial disparities in grant funding decrease the likelihood that Black scientists will achieve research independence, secure a tenure-track position, be granted tenure, and be promoted to Associate or Full Professor (Merton 1968; Cropsey et al. 2008; Taffe and Gilpin 2020).

ii. Scientific peer review of research grant applications Bias in peer review and discretionary funding decisions based on Institute priorities both contribute to racial disparities in NIH award rates (Ginther et al. 2011; Hoppe et al. 2019; Taffe and Gilpin 2021; Taffe 2020; Lauer et al. 2020). The Research Project (R01) grant is highly sought-after and makes up most research project grants (NIH 2019a); thus, it is the focus of this discussion. The first level of review of an R01 application is peer review conducted by mostly non-NIH scientists with relevant expertise. For applications deemed worthy of being discussed, the peer review committee assigns an impact score to indicate the overall scientific and technical merit of the application, considering the Significance, Investigator, Innovation, Approach, and Environment in assigning the impact score. Many of these criteria, such as prior applicant achievements, mentoring received, prestige and resources of the institution, and research topic choice are influenced by systemic racism and are subject to subconscious bias. For example, a Black applicant's prior achievements may be viewed with more skepticism and scrutiny, as under-represented minority faculty have reported experiencing "bias against or devaluation of an academic degree, experience or expertise" (Ransdell et al. 2021). Also, Black investigators may not receive the same mentoring and grant writing support at their institutions, creating a barrier for research success, as receiving mentoring reaps numerous career benefits such as a greater likelihood of holding a senior position and more career success, including stronger publication/grant records and performance evaluations, higher salaries, and faster career progression (CSR 2020; Ransdell et al. 2021; Tillman 2001). Regarding the research environment, minority-serving institutions may not have the same number of resources as predominantly white institutions (NIH 2019b). Over a third (33.9\%) of all Black investigators are from institutions in the lowest funding quintile, compared with $22.0 \%$ of white investigators (Hoppe et al. 2019). Lastly, NIH peer reviewers display content-based bias, tending to give better scores to applications closer to their area of expertise (Lee et al. 2013; Wessely 1998). Furthermore, Black applicants are more likely than white applicants to propose research topics that experience lower award rates, such as health disparities research (Hoppe et al. 2019; NIH 2019c).

After receiving an impact score, the application then receives a percentile rank, which is an approximate percentage of applications that received a better 
overall impact score from the study section during the past year. The percentile rank is compared to the payline, a "percentile-based funding cutoff point" calculated by many NIH institutes up to which nearly all R01 applications can be funded (NIH 2021b). Following peer review, a second level of review is performed by Institute and Center National Advisory Councils or Boards, but the Institute/Center director makes final funding decisions based on staff and Advisory Council/Board advice and considering overall impact scores, percentile rankings, paylines, and Institute/Center priorities.

Applications above the payline can be funded if they are a high priority for the Institute or Center (Rockey 2013). Such discretionary funding decisions also contribute to racial disparities in NIH funding (Taffe 2020; Hoppe et al. 2019; Lauer et al. 2020): from 2011-2015, 119 applications of white investigators with scores from the 35-59th percentile were awarded discretionary funding, compared to zero applications funded to Black investigators within this score range (Taffe 2020). Institute or Center assignment and topic choice also partially explain this disparity, as Black investigators are more likely to submit applications to Institutes or Centers with lower award rates and applications focused on topics of interest to under-represented minorities, whether or not submitted by a Black investigator, are more likely to be assigned to an Institute or Center with lower award rates (Lauer et al. 2020).

In addition to creating inequities, the current grant peer review system is slow and taxing on investigators (Crotty et al. 2020). Yet all the time and effort conducting peer review may be for naught; peer review percentile scores are poor predictors of productivity (Fang, Bowen, and Casadevall 2016) and there is low agreement among peer reviewers evaluating the same grant applications (Pier et al. 2018). Undoubtedly, this may contribute to the pervasive dissatisfaction with the current system and suggests reform in NIH peer review is needed (Pagano 2006; Fang and Casadevall 2009).

\section{iii. Current NIH policies to mitigate racial disparities in NIH funding}

A June 2020 blog post by the Director of the Center for Scientific Review (CSR) at the NIH outlined five current initiatives to mitigate individual and systemic bias in the peer review process (Byrnes 2020), which are briefly reviewed and evaluated here:

1) Development of bias-awareness training modules for reviewers and staff. Anti-bias training does not change biased behavior (Chang et al. 2019; Kaste 2020), and the impact of diversity training and prejudice reduction interventions remains largely unknown (Paluck and Green 2009).

2) Decouple the science- and idea-based aspects of peer review (significance, innovation, approach) from the person-based aspects (investigator, environment). This approach is unlikely to correct for biases in topic/significance such as biases against health disparities research and communitybased participatory research for minority populations (Hoppe et al. 2019) and is unlikely to overcome effects of systemic racism in academia such as disparities in mentoring and grant writing support.

3) Anonymizing applications. There is strong support for anonymizing the identity of applicants to peer reviewers (Liu et al. 2020) but it is difficult to make applications truly anonymous. Information contained in the application, such as the applicant's undergraduate or doctoral institution attended, may be used as a proxy for race/ethnicity (Ginther et al. 2011). Anonymizing applications is also difficult given the small number of researchers in a niche field and because investigators often cite their prior work in grant applications. A recent study by the CSR which anonymized investigator name in applications found that the anonymization was not entirely successful and scores for applications from Black investigators did not improve (CSR 2020).

4) Broaden the pool of reviewers with respect to career-stage. While this initiative may address racial disparities, the NIH must set specific goals to achieve study section diversity with respect to members' geographic distribution, gender, race, and ethnicity. The NIH is a taxpayer-funded entity tasked with improving the health of all Americans. Thus, specific diversity targets for reviewers on a study section should reflect 
the diversity of the nation rather than of the scientific community, as has been suggested (CSR 2020). In addition, the CSR should publish statistics for the race, ethnicity, gender, geographic location, career stage, and funding status for each study section at least annually to ensure transparency.

5) Identify and act against those who manipulate the review process. The NIH should be transparent and specifically describe the efforts that are taken to identify and take action against those found tampering with the peer review system. More importantly, the NIH must acknowledge that it is not immune to systemic and structural racism and create an actionable plan to address racial disparities in NIH funding.

\section{Policy options}

To date, the NIH/CSR have yet to outline concrete actions to correct disparities in funding and potential bias in peer review that result in a less diverse biomedical workforce. The current proposed initiatives will likely have only incremental impact and more urgent action by the NIH is warranted. Therefore, three main policy suggestions are:

\section{i. Option 1: Use affirmative action}

The funding disparity can be resolved by putting into place quota-based affirmative action procedures such as funding a certain percentage of applications from minority scientists or funding all applications from under-represented investigators that score above a specified threshold. The NIH implemented similar policies to redress the funding disparity for earlystage investigators (ESI), i.e., investigators within ten years of completing their terminal degree or medical residency. To increase the funding of ESI applications, in 2007, NIH implemented policies which included asking reviewers to be more lenient coupled with a relaxed payline that applied only to ESI applications (NIH 2017). This policy stabilized the trend of declining success rates for new investigators, with up to a 12 percentage-point increase in the probability of funding (Walsh, Moore, and Doyle 2018). A recent evaluation of the ESI policy estimated that as many as $54 \%$ of new investigators benefitted from the policy and otherwise would not have received funding (Walsh, Moore, and Doyle 2018). Similarly, the NIH should acknowledge the race/ethnicity of the investigator and make a concerted effort to see that a more diverse group of investigators is funded.

The fact that these policies have been successfully implemented for ESI suggests that there is a high probability of success if similar programs with respect to historically under-represented individuals are implemented. In addition to addressing funding disparities in race/ethnicity for defined groups, to achieve equity, this program should be expanded to include other groups under-represented in STEM including women, investigators with reported disabilities, and investigators of certain sexual identities (Woolston 2020; Ley and Hamilton 2008; Pohlhaus et al. 2011).

ii. Option 2: Prioritize research topics that align with interests of under-represented minority investigators While investigators have expressed support for Option 1 to close the funding gap, which can be implemented relatively easily (CSR 2020), it does not resolve bias in applications such as bias against research topic choice. A recent study found that topic choice alone accounted for over $20 \%$ of the funding gap between Black scientists and their white colleagues (Hoppe et al. 2019). Proposals from Black applicants are skewed towards a relatively small group of topics, e.g., fifteen topics accounted for $50 \%$ of applications submitted by Black investigators between 2011-2015 (Lauer et al. 2020). The NIH should create new funding opportunities for research topics more often proposed by under-represented investigators and topics important to underrepresented communities. Doing so will not only safeguard these proposals from discrimination during the review process but will also further demonstrate the NIH's commitment to eliminating disparities and promoting health equity (Carnethon, Kershaw, and Kandula 2020).

Furthermore, Institutes and Centers should also prioritize these research topics when making discretionary funding decisions. A study estimated that 119 applications from white investigators with scores in the 35-59 th percentile range were awarded discretionary funding versus zero applications from Black investigators with scores in the same range. The lowest ranked funded application from a Black investigator ranked in the $30-34^{\text {th }}$ percentile range compared to the 55-59th percentile range for white investigators. Prioritizing the funding of applications 
from Black scientists ranked in the $15-35^{\text {th }}$ percentile range instead of applications from white scientists that ranked outside the top $35 \%$ of applications would improve racial disparities in funding (Taffe and Gilpin 2021).

This policy would not require formal programmatic change and therefore could be implemented immediately. It would only require changes in discretionary decisions that could be made by prioritizing research topics more often proposed by under-represented investigators and topics important to under-represented communities. However, if $20 \%$ of the funding gap is explained by topic choice, then the $\sim 80 \%$ of the gap not explained by topic choice may not be resolved with this approach.

\section{iii. Option 3: Implement a modified lottery}

A modified lottery may be the most equitable way to award research funds. It has become increasingly clear that the current peer review process is not effective and is deeply subjective (Fang, Bowen, and Casadevall 2016; Pier et al. 2018; Fang and Casadevall 2016; Graves, Barnett, and Clarke 2011; Hayden 2015). Above some threshold, the likelihood of being recommended for funding is mostly a matter of chance (Pier et al. 2018). In a modified lottery, peer review is used to identify the most meritorious proposals above a given threshold, from which funded applications are selected at random (Fang and Casadevall 2016). The idea is not impracticable; a growing number of research agencies are awarding grants partly through random selection (Adam 2019).

A modified lottery for NIH fund allocation would have many advantages over the current system including time and cost savings, but the fundamental advantage is in creating equity and improving diversity regarding race/ethnicity, gender, and career status. Should disparities continue, the acceptance criteria for entering the lottery could be modified to weight individuals under-represented in STEM. This approach would correct for other biases inherent in all individuals, such as cronyism and preference for a particular research topic or institution.

While this approach may allow some research areas to be under-funded due to chance, to remedy this, Institute/Center directors could make discretionary funding decisions as they do now. The biggest drawback to this policy is that many researchers who have been successful navigating the current $\mathrm{NIH}$ funding schema would likely oppose such drastic changes, especially if they are less likely to benefit from the lottery system.

\section{Policy recommendation: Implement Options 1 and 2 immediately, with Option 3 in the pipeline} I recommend implementing Options 1 and 2 immediately while working towards implementing Option 3. A drastic overhaul of NIH grant funding is needed not only to increase equity, but also to increase scientific productivity and propel the intellectual creativity and risk-taking the US needs to retain its global leadership in STEM. Thus, I support Option 3, a modified lottery, and encourage other scientists who are also in favor to advocate for this policy. This policy would ensure funds are distributed in a fair and transparent manner. The cost savings of foregoing extensive grant review could be applied to other initiatives such as awarding more $\mathrm{T}$ and $\mathrm{F}$ fellowships. However, researchers may be less likely to support this policy and it could take a long time to implement when needed change is urgent.

While Option 1 may help to address funding disparities in race/ethnicity for defined groups, unless expanded, it would not fully close the gap for other groups under-represented in STEM including women, investigators with reported disabilities, and investigators of certain sexual identities (Woolston 2020; Ley and Hamilton 2008; Pohlhaus et al. 2011). However, the NIH has previously demonstrated that this strategy can be successfully implemented quickly. For this policy to be fully successful, it would have to be combined with Option 2. A disadvantage to these policies is that investigators would remain tasked with writing, re-submitting, and reviewing grants when that time could be used more productively. In conclusion, while they may be less effective in reducing biases in funding decisions, I recommend implementing Options 1 and 2 immediately, because needed change is urgent and the NIH has previously demonstrated such policies can be implemented quickly, while pursuing the more effective Option 3 as the long-term solution to ensuring research funds are distributed in a fair and transparent way. 


\section{References}

Adam, David. 2019. "Science Funders Gamble on Grant Lotteries." Nature 575 (7784): 574-75. https://doi.org/10.1038/d41586-019-03572-7.

Association of American Medical Colleges. 2018. "Figure 15: Percentage of Full-Time US Medical School Faculty by Race/Ethnicity, 2018." 2018. https://www.aamc.org/datareports/workforce/interactive-data/figure-15percentage-full-time-us-medical-school-facultyrace/ethnicity-2018.

Benish, Sarah. 2018. "Meeting STEM Workforce Demands by Diversifying STEM." Journal of Science Policy \& Governance 13 (1).

Bianchini, Julie A. 2011. Expanding Underrepresented Minority Participation: America's Science and Technology Talent at the Crossroads. Washington, District of Columbia: National Academies Press.

Byrnes, Noni. 2020. "Race \& Peer Review." NIH Center for Scientific Review. June 12, 2020.

https://www.csr.nih.gov/reviewmatters/2020/0 6/12/race-peer-review/.

Carnethon, Mercedes R., Kiarri N. Kershaw, and Namratha R. Kandula. 2020. "Disparities Research, Disparities Researchers, and Health Equity." JAMA 323 (3): 211.

https://doi.org/10.1001/jama.2019.19329.

Chang, Edward H., Katherine L. Milkman, Dena M. Gromet, Robert W. Rebele, Cade Massey, Angela L. Duckworth, and Adam M. Grant. 2019. "The Mixed Effects of Online Diversity Training." Proceedings of the National Academy of Sciences 116 (16): 7778-83.

https://doi.org/10.1073/pnas.1816076116.

Cropsey, Karen L., Saba W. Masho, Rita Shiang, Veronica Sikka, Susan G. Kornstein, Carol L. Hampton, and the Committee on the Status of Women and Minorities, Virginia Commonwealth University School of Medicine, Medical College of Virginia Campus. 2008. "Why Do Faculty Leave? Reasons for Attrition of Women and Minority Faculty from a Medical School: Four-Year Results." Journal of Women's Health 17 (7): 1111-18.

https://doi.org/10.1089/jwh.2007.0582.

Crotty, Shane, Catherine Blish, Ken Cadwell, Hongbo Chi, Ananda Goldrath, Douglas Green, Susan M. Kaech, et al. 2020. "Reinvigorating NIH Grant Peer Review." Immunity 52 (1): 1-3. https://doi.org/10.1016/j.immuni.2019.12.016.

CSR (NIH Center for Scientific Review). 2020. "CSR Content Analysis: Forums on Racial Disparities in Peer Review and More."

https://public.csr.nih.gov/sites/default/files/20 $\underline{20-}$

09/CSR July 2020 Racial Disparities in Funding comment summary.pdf.
Dzau, Victor J., and Harvey V. Fineberg. 2015. "Restore the US Lead in Biomedical Research." JAMA 313 (2): 143.

https://doi.org/10.1001/jama.2014.17660.

Dzirasa, Kafui. 2020. "Revising the a Priori Hypothesis: Systemic Racism Has Penetrated Scientific Funding." Cell 183 (3): 576-79. https://doi.org/10.1016/i.cell.2020.09.026.

Fairle, Robert W., Florian Hoffmann, and Philip Oreopoulos. 2014. "A Community College Instructor like Me: Race and Ethnicity Interactions in the Classroom." American Economic Review 104 (8): 2567-91.

Fang, Ferric C., Anthony Bowen, and Arturo Casadevall. 2016. "NIH Peer Review Percentile Scores Are Poorly Predictive of Grant Productivity." ELife 5 (February): e13323. https://doi.org/10.7554/eLife.13323.

Fang, Ferric C., and Arturo Casadevall. 2009. "NIH Peer Review Reform-Change We Need, or Lipstick on a Pig?" Infection and Immunity 77 (3): 929-32. https://doi.org/10.1128/IAI.01567-08.

Fang, Ferric C., and Arturo Casadevall. 2016. "Research Funding: The Case for a Modified Lottery." MBio 7 (2): e00422-16, /mbio/7/2/e00422-16.atom. https://doi.org/10.1128/mBio.00422-16.

Finkelstein, Martin J., Valerie Martin Conley, and Jack H. Schuster. 2016. "Taking the Measure of Faculty Diversity." TIAA Institute.

https://www.tiaainstitute.org/sites/default/files /presentations/2017$02 /$ taking the measure of faculty diversity.pdf.

Gibbs, Kenneth D., Jacob Basson, Imam M. Xierali, and David A. Broniatowski. 2016. "Decoupling of the Minority PhD Talent Pool and Assistant Professor Hiring in Medical School Basic Science Departments in the US." ELife 5 (November): e21393.

https://doi.org/10.7554/eLife.21393.

Ginther, Donna K., Shulamit Kahn, and Walter T. Schaffer. 2016. "Gender, Race/Ethnicity, and National Institutes of Health R01 Research Awards: Is There Evidence of a Double Bind for Women of Color?" Academic Medicine 91 (8): 1098-1107. https://doi.org/10.1097/ACM.00000000000012 $\underline{78}$.

Ginther, Donna K., Walter T. Schaffer, Joshua Schnell, Beth Masimore, Faye Liu, Laurel L. Haak, and Raynard Kington. 2011. "Race, Ethnicity, and NIH Research Awards." Science (New York, N.Y.) 333 (6045): 1015-19. https://doi.org/10.1126/science.1196783.

Graves, N., A. G. Barnett, and P. Clarke. 2011. "Funding Grant Proposals for Scientific Research: Retrospective Analysis of Scores by Members of Grant Review Panel." BMJ 343 (sep27 1): d4797d4797. https://doi.org/10.1136/bmi.d4797. 
Hayden, Erika C. 2015. "Racial Bias Continues to Haunt NIH Grants." Nature 527 (7578): 286-87. https://doi.org/10.1038/527286a.

Hoppe, Travis A., Aviva Litovitz, Kristine A. Willis, Rebecca A. Meseroll, Matthew J. Perkins, B. Ian Hutchins, Alison F. Davis, et al. 2019. "Topic Choice Contributes to the Lower Rate of NIH Awards to African-American/Black Scientists." Science Advances 5 (10): eaaw7238.

https://doi.org/10.1126/sciadv.aaw7238.

Kaste, Martine. 2020. "NYPD Study: Implicit Bias Training Changes Minds, Not Necessarily Behavior. NPR." National Public Radio. 2020.

https://www.npr.org/2020/09/10/909380525/ nypd-study-implicit-bias-training-changesminds-not-necessarily-behavior.

Lauer, Michael, Jamie Doyle, Joy Wang, and Deepshikha Roychowdhury. 2020. "National Institutes of Health Institute and Center Award Rates and Funding Disparities." Preprint. Scientific Communication and Education. https://doi.org/10.1101/2020.12.27.424490.

Lee, Carole J., Cassidy R. Sugimoto, Guo Zhang, and Blaise Cronin. 2013. "Bias in Peer Review." Journal of the American Society for Information Science and Technology 64 (1): 2-17. https://doi.org/10.1002/asi.22784.

Ley, T. J., and B. H. Hamilton. 2008. "SOCIOLOGY: The Gender Gap in NIH Grant Applications." Science 322 (5907): 1472-74.

https://doi.org/10.1126/science.1165878.

Liu, Mengyao, Vernon Choy, Philip Clarke, Adrian Barnett, Tony Blakely, and Lucy Pomeroy. 2020. "The Acceptability of Using a Lottery to Allocate Research Funding: A Survey of Applicants." Research Integrity and Peer Review 5 (1): 3. https://doi.org/10.1186/s41073-019-0089-z.

McGee, Richard, Suman Saran, and Terry A. Krulwich. 2012. "Diversity in the Biomedical Research Workforce: Developing Talent." The Mount Sinai Journal of Medicine, New York 79 (3): 397-411.

https://doi.org/10.1002/msj.21310.

Merton, R. K. 1968. "The Matthew Effect in Science: The Reward and Communication Systems of Science Are Considered." Science 159 (3810): 56-63. https://doi.org/10.1126/science.159.3810.56.

Moses, Hamilton, David H. M. Matheson, Sarah CairnsSmith, Benjamin P. George, Chase Palisch, and E. Ray Dorsey. 2015. "The Anatomy of Medical Research: US and International Comparisons." JAMA 313 (2): 174.

https://doi.org/10.1001/jama.2014.15939.
National Center for Education Statistics, US Department of Education. 2020. "Table 315.20. Full-Time Faculty in Degree-Granting Postsecondary Institutions, by Race/Ethnicity, Sex, and Academic Rank: Fall 2015, Fall 2017, and Fall 2018." Accessed May 1, 2021.

https://nces.ed.gov/fastfacts/display.asp?id=61.

NIH. 2017. "A History of New and Early Stage Investigator Policies and Data." August 29, 2017.

https://grants.nih.gov/policy/earlyinvestigators/history.htm.

NIH. 2019a. "NIH Research Project Grant Program (R01)." NIH Central Resource for Grants and Funding Information. February 27, 2019. https://grants.nih.gov/grants/funding/r01.htm.

NIH. 2019b. "NIH Awards by Location \& Organization." NIH Research Portfolio Online Reporting Tools (RePORT). December 12, 2019.

https://report.nih.gov/award/index.cfm?ot=\&fy $=2020 \&$ state $=$ USS,AL,AK,AZ,AR,CA,CO,CT,DE,DC,F

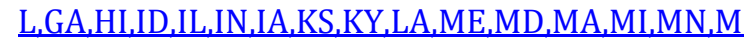
S,MO,MT,NE,NV,NH,NJ,NM,NY,NC,ND,OH,OK,OR,P $\underline{\text { A,RI,SC,SD,TN,TX,UT,VT,VA,WA,WV,WI,WY\&ic }=\& \mathrm{f}}$ $\underline{m=\& o r g i d}=\&$ distr $=\& r f a=\& o m=n \& p i d=\& v i e w=$ sta tedetail.

NIH. 2019c. "Research Topic Contributes to Persistent Gap in NIH Research Grants to Black Scientists." News Releases. NIH Office of the Director (OD). October 9, 2019.

https://www.nih.gov/news-events/newsreleases/research-topic-contributes-persistentgap-nih-research-grants-Black-scientists.

NIH. 2021a. "Racial Disparities in NIH Funding." NIH Office of the Director (OD), Scientific Workforce Diversity. Accessed April 15, 2021. https://diversity.nih.gov/buildingevidence/racial-disparities-nih-funding.

NIH. 2021b. "Glossary \& Acronym List." NIH Central Resource for Grants and Funding Information. Accessed April 30, 2021.

https://grants.nih.gov/grants/glossary.htm.

Pagano, Michele. 2006. "American Idol and NIH Grant Review." Cell 126 (4): 637-38. https://doi.org/10.1016/j.cell.2006.08.004.

Paluck, Elizabeth Levy, and Donald P. Green. 2009. "Prejudice Reduction: What Works? A Review and Assessment of Research and Practice." Annual Review of Psychology 60 (1): 339-67. https://doi.org/10.1146/annurev.psych.60.1107 07.163607.

Pier, Elizabeth L., Markus Brauer, Amarette Filut, Anna Kaatz, Joshua Raclaw, Mitchell J. Nathan, Cecilia E. Ford, and Molly Carnes. 2018. "Low Agreement among Reviewers Evaluating the Same NIH Grant Applications." Proceedings of the National Academy of Sciences 115 (12): 2952-57. https://doi.org/10.1073/pnas.1714379115. 
Pohlhaus, Jennifer Reineke, Hong Jiang, Robin M. Wagner, Walter T. Schaffer, and Vivian W. Pinn. 2011. "Sex Differences in Application, Success, and Funding Rates for NIH Extramural Programs:" Academic Medicine 86 (6): 759-67. https://doi.org/10.1097/ACM.0b013e31821836f f.

Ransdell, Lynda, Taylor Lane, Anna Schwartz, Heidi Wayment, and Julie Baldwin. 2021. "Mentoring New and Early-Stage Investigators and Underrepresented Minority Faculty for Research Success in Health-Related Fields: An Integrative Literature Review (2010-2020)." International Journal of Environmental Research and Public Health 18 (2): 432.

https://doi.org/10.3390/ijerph18020432.

Rockey, Sally. 2013. "Revisiting the Relationship Between Paylines and Success Rates." National Institutes of Health Office of Extramural Research Extramural NEXUS. January 11, 2013.

https://nexus.od.nih.gov/all/2013/01/11/revisit ing-the-relationship-between-paylines-andsuccess-rates/.

Sekar, Havya. 2020. "National Institutes of Health (NIH) Funding: FY1995-FY2021." Congressional Research Service.

www.crs.gov.

Taffe, Michael A. 2020. "'Merit' and the NIH Disparity of Grant Award to Black PIs." Drugmonkey (blog). June 10, 2020.

https://drugmonkey.scientopia.org/2020/06/10 Lmerit-and-the-nih-disparity-of-grant-award-toBlack-pis/.

Taffe, Michael A., and Nicholas W. Gilpin. 2021. "Racial Inequity in Grant Funding from the US National Institutes of Health." ELife 10 (January). https://doi.org/10.7554/eLife.65697.

Taffe, Michael A., and Nicholas W. Gilpin. 2020. "Racial Inequity in Federal Grant Funding." Preprint. PsyArXiv.

https://doi.org/10.31234/osf.io/ucb62.
The White House. 2021. FACT SHEET: The American Jobs Plan. March 31, 2021.

https://www.whitehouse.gov/briefingroom/statements-releases/2021/03/31/factsheet-the-american-jobs-plan/.

Thomas, David A., and Robin J. Ely. 1996. "Making Differences Matter: A New Paradigm for Managing Diversity." Harvard Business Review, no. 75: 7990.

Tillman, Linda C. 2001. "Mentoring African American Faculty in Predominantly White Institutions." Research in Higher Education 42 (3): 295-325. https://doi.org/10.1023/A:1018822006485.

Tollefson, Jeff, Amy Maxmen, Ariana Remmel, Nidhi Subbaraman, and Alexandra Witze. 2021. "Biden Pursues Giant Boost for Science Spending." Nature 592 (7855): 498-99. https://doi.org/10.1038/d41586-021-00897-0.

United States (US) Census Bureau. 2019. "Table DP05. ACS Demographics and Housing Estimates." 2019 American Community Survey 1-Year Estimates. 2019.

https://data.census.gov/cedsci/profile?q=United \%20States\&g=0100000US.

Walsh, Rachael, Robert F. Moore, and Jamie Mihoko Doyle. 2018. "An Evaluation of the National Institutes of Health Early Stage Investigator Policy: Using Existing Data to Evaluate Federal Policy." Research Evaluation 27 (4): 380-87. https://doi.org/10.1093/reseval/rvy012.

Wessely, Simon. 1998. "Peer Review of Grant Applications: What Do We Know?" The Lancet 352 (9124): 3015.

https://doi.org/10.1016/S0140-6736(97)111291.

Woolston, Chris. 2020. "Fewer US Researchers Are Disclosing Disabilities on NIH Grant Applications." Nature, March, d41586-020-00887-88. https://doi.org/10.1038/d41586-020-00887-8.

Nicole Comfort is a 5th year doctoral student in the Environmental Health Sciences Department at Columbia University studying extracellular vesicle microRNA as biomarkers of environmental exposures and disease. She holds a BS in Behavioral Neuroscience from Northeastern University. Nicole has an active interest in science advocacy and policy, and is committed to advancing diversity, equity, and inclusion in the sciences.

\section{Acknowledgements}

NC is supported by the National Institutes of Health Ruth L. Kirschstein National Research Service Award Individual Predoctoral Fellowship (F31ES030973).

\section{Disclaimer}

Author's views do not necessarily reflect those of her department or sponsors. 